\title{
配管の周溶接残留応力評価*
}

\author{
寺前哲夫*1, 田中良彦*1, 松 永智 典*2
}

\section{The Evaluation of Residual Stress of Girth Welded Pipe Joint}

\author{
Tetsuo TERAMAE*3, Yoshihiko TANAKA and Tomonori MATSUNAGA \\ ${ }^{* 3}$ Materials Engieering Center, Tokyo Electric Power Company, \\ 4-1 Egasaki-cho, Tsurumi-ku, Yokohama-shi, Kanagawa, 230-8510 Japan
}

\begin{abstract}
SCC life estimation is very important to maintain the safety of nuclear power plants. One of the main research tasks in SCC life estimation is the evaluation of welding residual stress, which is the dominant stress causing SCC of nuclear power plants. Although some analytical research works have been conducted to clarify the welding residual stress, most of them are 2-dimensional analysis. In this paper, the authors report the residual stress of girth weld pipe obtained by axi-symmetrical and 3-dimensional numerical analyses, and these analytical results are compared with experimental residual stress measured by neutron diffraction method. It is concluded that the 3 dimensional analysis shows good correlation with measured results. And, if the temperature history is well simulated, the difference of residual stress between axi-symmetric and 3 dimensional analyses is relatively small so that axi-symmetric analysis can be used for preliminary residual stress analysis.
\end{abstract}

Key Words : Nuclear Power Plant, Piping, SCC, Welding Residual Stress, Test Numerical Analysis

\section{1. 緒 言}

原子力配管系の SCC 寿命評価において，主要な応力 である溶接残留応力を精度よく推定することは重要な 課題である.

望月等 ${ }^{1)}$ は厚板を貫通する配管周溶接残留応力を 2 次元軸対称問題として解析しているが，実機の溶接は 3 次元問題であり, 解析精度を高めるには 3 次元解析 が必要である. Dong 等 ${ }^{2)}$ は shel1 要素を用い, 溶接入 熱は最後のパスのみを考慮して, 配管周溶接継手の 3 次元残留応力解析を行っている. 笠等 ${ }^{3)}$ は配管周溶接 継手について，軸方向および径方向に仮想バネを入れ ることにより，3 次元溶接を模擬した 2 次元解析を行 っている. 小川等 ${ }^{4)}$ は圧力容器鏡板に斜めに溶接され る場合について 3 次元残留応力解析を行っているが, 熱源移動を考慮せず，各パス毎に一様入熱として近似 的に解いている.

このように, 現状の計算機の能力が 3 次元解析を行 うには不十分であるため, 残留応力解析は 2 次元解析 あるいは近似的な 3 次元解析を行うに止まっている.

* 原稿受付 2007 年 7 月 25 日

*1 正員, 東京電力(株)技術開発研究所材料技術センター (裂 230-8510 横浜市鶴見区江ヶ崎町 4-1).

*2 東電工業 (株) 技術部 (画 108-0074 東京都港区高輪 1-3-13).

E-mail : Teramae.Tetsuo@tepco.co.jp
英国 ${ }^{5)}$ では溶接残留応力に関するプロジェクトの中で 解析法の検討を行っており，その中で 2 次元解析と 3 次元解析による残留応力の比較を行うことにしている.

以上述べたように，これまで 3 次元解析を用いた残 留応力評価はほとんど行われていない. そこで, 本研 究では 2 次元軸対称モデルおよび 3 次元モデルによる 溶接残留応力解析を行い, 実験による残留応力測定結 果と比較する，まず，軸対称モデルにより，SCC 評価 上最も重要な軸方向残留応力に及ぼす伝熱条件, 応力 ひずみ関係などの影響を明らかにする. 次に, 溶接試 験条件に基づいて, 周溶接継手に対して 2 次元軸対称 解析，および実際の溶接トーチによる移動入熱を考慮 した 3 次元残留応力解析を行い, 中性子回折法による 残留応力測定結果と比較して，それぞれの解析の妥当 性を検討する.

\section{2. 溶接試験体の製作と残留応力の測定}

\section{1 溶接試験体の製作 厚さ $21.4 \mathrm{~mm}$, 外径}

$318.5 \mathrm{~mm}$ ，長さ $250 \mathrm{~mm}$ の SUS316L 製 $300 \mathrm{~A}$ 配管 2 本を周 溶接し, 長さ $500 \mathrm{~mm}$ の溶接試験体を製作した. 図 1 に 開先形状（U 型狭開先）およひ溶接パスを示す. 溶接 はTIG 溶接であり, 溶接速度は平均 $1.7 \mathrm{~mm} / \mathrm{s}$ ，入熱は 平均 $1200 \mathrm{~J} / \mathrm{mm}$ ，層間温度は $180^{\circ} \mathrm{C}$ 以下である. また, 溶接部近傍において内面 14 点, 外面 14 点および開先 部 1 点, 計 29 点の熱電対を取り付け, 溶接中の温度履 
歴を測定した. 図 2 に外面での熱電対の取り付け状況 を示す。
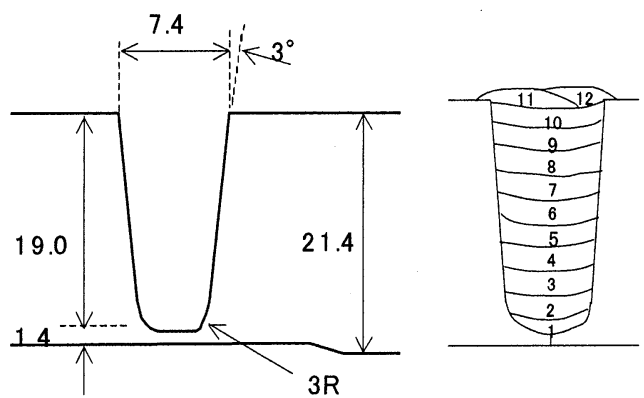

(a) Joint configuration

(b) Pass outline
ABAQUS を用いて, 軸対称モデルにより伝熱解析および 応力解析を行った.

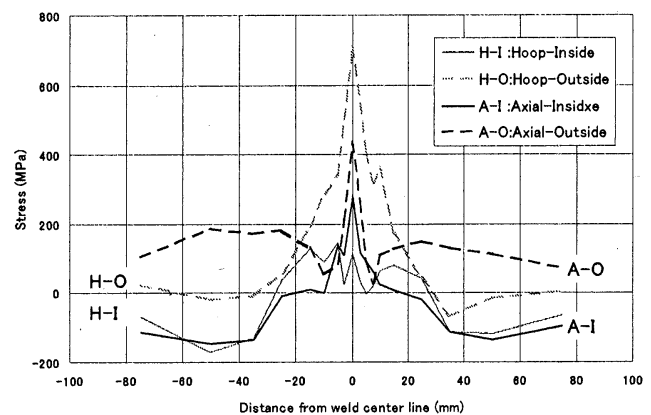

Fig. 1 Details of welding

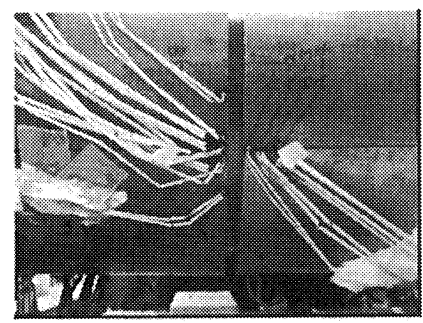

Fig. 2 Location of thermocouples along the weld line on outer surface

\section{2 溶接残留応力の測定 中性子回折法により} 溶接残留応力を測定した。測定点数は溶接部を中心に 長手方向 $\pm 80 \mathrm{~mm}$ の範囲を対称に 17 点, 厚さ方向に $0.9 \mathrm{~mm}$ 毎に最大 20 点, 総計 146 点であり, 軸方向, 周 方向, 径方向の歪みを測定し, 弾性則により残留応力 を算定した．中性子ビーム幅は $1.5 \mathrm{~mm}$ ，波長は軸方向 歪み測定時 $0.17 \mathrm{~nm}$ ，周方向および径方向歪み測定時 $0.14 \mathrm{~nm}$ である. なお, 周方向歪み測定のため, 中心角 90 度位置で溶接部周方向 2 力所に開口を設けた. 図 3 に残留応力の軸方向分布測定結果を示す．図中，内面 側は溶接部内面から $1.1 \mathrm{~mm}$ の位置での測定結果, 外面 側は $18.2 \mathrm{~mm}$ 位置での測定結果を示している. なお, 今 回の測定では無歪み状態の参照サンプルとして溶接金 属部ではなく母材のデータを用いているため，溶接金 属部での測定には誤差が含まれている.

\section{3. 軲対称パラメトリック残留応力解析}

3. 1 解析条件 残留応力に及ぼす各種パラメ 一タの影響を明らかにするため, 沉用解析コード

Fig. 3 Axial distribution of measured residual stress

解析においては 11 パスと 12 パスを合わせ， 1 回の パスとした. また，材料特性は望月の文献 ${ }^{1)}$ に与えら れているデータを用いた．以下に解析の基本条件を示 す.
・変形

・使用要素

- 要素分割数

- 入熱波形

・最大入熱

・表面熱伝達率

・配管表面輻射率

・溶融凝固潜熱

・歪み硬化

・応力歪関係

・冷却時間

・アニール温度

なお，歪硬化は $10 \%$ 歪までとし，それ以上の歪みに対 しては完全塑性とみなした。

3. 2 解析結果 前述の基本条件をベースに予 備解析を行い, 以下の結果を得た.

- 大変形解析結果は微小変形解析結果と大差なく, 大 变形の影響は小さい.

- 要素分割を基本条件の約 2 倍とした場合および要素 次数を 1 次から 2 次に変更した場合について解析を 行ったが，解析結果は大差なく, 基本条件程度の要 素分割で十分な解析精度が得られる。

・伝熱解析において最大温度増分 $30^{\circ} \mathrm{C} て ゙$ 安定解が得ら れたが，50ㄷ とすると途中で計算が発散した.

・今回の解析条件では熱伝達率, 輻射率, 潜熱などが 溶接残留応力に及ぼす影響は小さい。 
次に表 1 に示す解析条件でパラメトリック解析を行 い, 残留応力に及ぼす影響を評価した. 変化させた項 目はマスクを施している. 図 4 に溶接中央における軸 方向残留応力の厚さ方向分布を示す.

Table 1 Condition of axi-symmetric parametric study
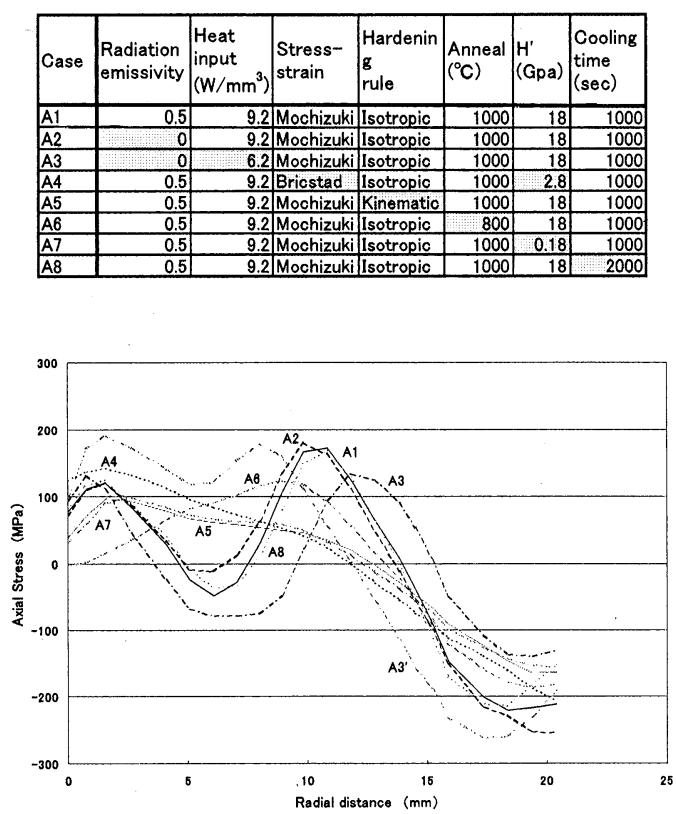

Fig. 4 Radial distribution of axial residual stress

最大入熱を $6.2 \mathrm{w} / \mathrm{mm}^{3}$ と小さくした $\mathrm{A} 3$ では, $9.2 \mathrm{w} / \mathrm{mm}^{3}$ の $\mathrm{A} 1$ と比較して, 各パスとも溶接金属部の最大温度は 約 $350^{\circ} \mathrm{C}$ 低下しており, それに伴い残留応力も低下し ている. Bricstad ${ }^{6)}$ は，「最後の溶接パスの位置がそ の直前の数パスの位置と大きくかわらないのであれば, 最終的な残留応力分布は最後の溶接パスに支配され る.」と指摘している.この点について確認するため, A3 の条件で 11 パスのみ熱入力を 2 倍として解析 A3' を実施した. A3 と比較して, 軸方向残留応力は大き くなっているとともに応力の線形成分が大きくなって いる. また, 応力分布形の変化は他のケースに比べて 大きく, 最終パスの入熱量が残留応力分布に大きく影 響している事を示している. 残留心力には自己平衡成分と 周りの弾性体による曲け変形敂束こ伴う線形単生㐫力か浛まれ ており, 変形够束の影響が大きければ線形成分が大きくなり, 逆 であれば自己平衡成分が大きくなる。

Bricstad の応力歪関係データ ${ }^{6)}$ を用いた A4 の場合 は, A1 の望月のデータによる解析と比べて, 応力值が 低く, 残留応力分布は線形性が強い.これは望月のデ 一タを用いた場合に自己平衡性が強いのと対照的であ
る. 図 5 に両者の降伏応力を比較するが, Bricstadの データの方が望月のデータに比べて降伏応力が小さい. 同様のことは，硬化則を等方硬化則から移動硬化則に 変えた $A 5$, および等方硬化則で歪み硬化率を $1 / 100$ に 低減した A7 についても言える.これらはいずれもは降 伏応力を小さくしたことと同じである. 以上のことか ら, 降伏応力を大きくすると軸方向残留応力分布にお ける自己平衡成分が大きくなり，相対的に線形成分が 小さくなると考えられる.

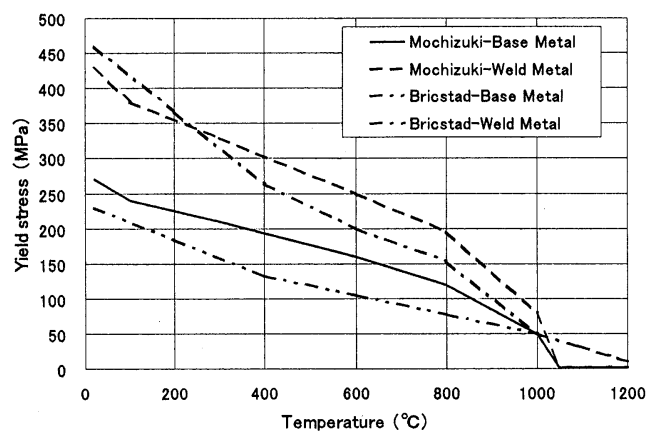

Fig. 5 Yield stress used in parametric calculation

一方，高温では材料の塑性歪み履歴が消失すると考 えられるが, ABAQUS はこの点を考慮できる「アニール」 解析機能を有している. そこで，アニール温度を $1000^{\circ} \mathrm{C}$ (A1) から $800^{\circ} \mathrm{C}$ に低下させたA6 の解析を行っ たが, 残留応力は減少している. また, 冷却時間を 1000s（A1）から 2000s に増やしたA8 では残留応力分 布の変化は小さい.

\section{4. 試験結果との比較}

4. 1 解析条件 次に, 前章の結果を参考にして, 軸対称および 3 次元モデルにより試験結果との比較計 算を実施した. 軸対称解析での入熱は図 6 のような台 形波形とし, 内面溶接部近傍での温度が測定結果に近 くなるように, 各パスの最大入熱を決定した. そのほ かの解析条件を以下に示す.

$\begin{array}{ll}\text { 表面熱伝達率 } & 0.928 \times 10^{-5} \mathrm{w} / \mathrm{mm} 2 /{ }^{\circ} \mathrm{C} \\ \text { 輻射 } & \text { 輻射率 } 0.5 \\ \text { 溶融凝固潜熱 } & 278 \mathrm{~J} / \mathrm{g} \\ \text { 歪み硬化則 } & \text { 等方硬化, 移動硬化 } \\ \text { 応力歪関係 } & \text { 望月 }{ }^{1)}, \mathrm{Bricstad}^{6)} \\ \text { アニール温度 } & 700^{\circ} \mathrm{C}, 800^{\circ} \mathrm{C}, 900^{\circ} \mathrm{C}\end{array}$




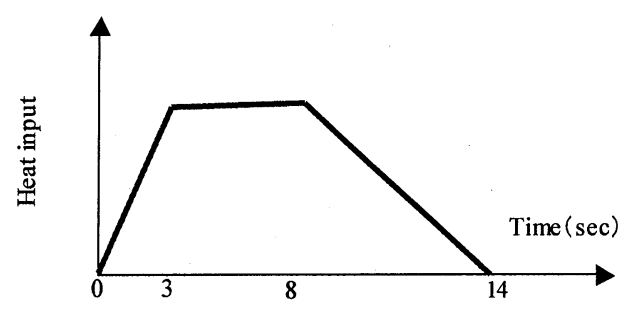

Fig. 6 Heat input for axi-symmetric analysis

一方，使用した計算機の能力では配管周方向溶接継 ぎ手の 360 度全周の 3 次元解析は膨大な時間がかかる ことから, 3 次元解析においては現状解析可能な 45 度 部分モデルを用いた. このモデルは軸対称要素分割を 周方向に 45 度回転させたもので, 6 面体 1 次要素で周 方向に 20 要素に等分割した. 両端面は, 伝熱解析では 断熱，応力解析では周方向変形拘束とした. 図 7 に入 熱波形を示すが，溶接トーチ位置を中心として前後対 称な台形波入熱とした. 溶接トーチ速度は $1.7 \mathrm{~mm} / \mathrm{s}$, 溶融幅は $15 \mathrm{~mm}$ と仮定し, 入熱時間は溶融幅をトーチ速 度で割った時間 8.8 秒とした. ただし，前後 1 秒は 入熱の開始および終了時間とし，総入熱量が実溶接の 值と合うように各パス毎に最大入熱の值を調整した。

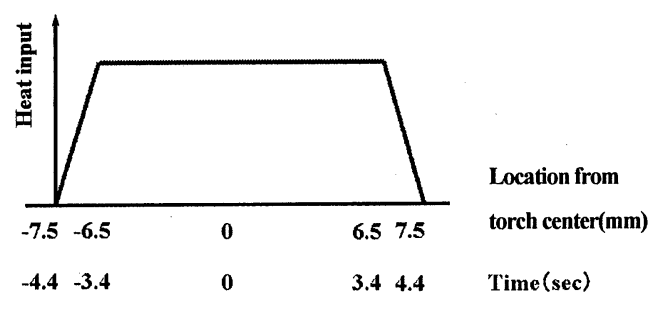

Fig. 7 Heat input for 3 dimensional analysis

その他の解析条件を以下に示す.

$\begin{array}{ll}\text { 表面熱伝達率 } & 0.928 \times 10^{-5} \mathrm{w} / \mathrm{mm} 2 /{ }^{\circ} \mathrm{C} \\ \text { 輻射 } & \text { 輻射率 } 0.5 \\ \text { 溶融凝固潜熱 } & 278 \mathrm{~J} / \mathrm{g} \\ \text { 歪み硬化則 } & \text { 等方硬化 } \\ \text { 応力歪関係 } & \text { 望月 }{ }^{1)} \\ \text { アニール温度 } & 800^{\circ} \mathrm{C}\end{array}$.

なお，軸対称および 3 次元解析とも，100\%歪まで歪 硬化とし，それ以上は完全塑性とみなした。

\section{2 解析結果}

（1）伀熱解析 図8に溶金に最も近い内外面位置 での最大温度を測定結果と比較して示す.温度測定は, 内面側は開先から $2.5 \mathrm{~mm}$, 外面側は開先から $2.2 \mathrm{~mm} の$ 位置である．解析值はこれらの測定位置に最も近い節 点での值を用いた，本図にお゙いて, 内面側解析結果は 軸対称および 3 次元とも測定結果と比較的良く合って いるが，外面側解析結果は測定結果よりも小さく， 6 パス以降その差が拡大している. この理由として溶接 トーチからの輻射熱の影響が挙げられる.すなわち, 外面側測定位置では溶接トーチからの輻射熱を受ける のに対して, 解析ではこれを考慮していないため, 解 析值が測定值よりも低くなったものと考えられる.

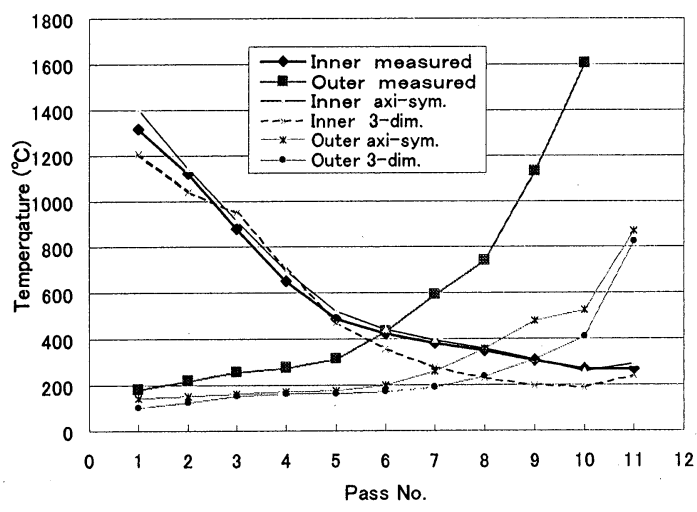

Fig.8 Comparison of maximum temperature

\section{(2) 応力解析}

まず, 軸対称解析により残留応力分布に及ぼすアニ 一ル温度, 硬化則および応力歪関係の影響を検討した. 望月の忘力歪関係, 等方硬化則を用い, アニール温度 を $700^{\circ} \mathrm{C}, 800^{\circ} \mathrm{C}, 900^{\circ} \mathrm{C}$ 変えて得られた溶接中央で の軸方向残留応力の厚さ方向分布を測定結果と比較し て図 9 に示すが，アニール温度の影響は小さい. 次 に, アニール温度 $700^{\circ} \mathrm{C}$, 等方硬化則として, 望月お よび Bricstad の応力歪関係を用いて得られた溶接中央 および溶接界面での軸方向残留応力の厚さ方向分布を， 測定結果と比較して図 10 に示す. なお, 溶接中心から $3 \mathrm{~mm}$ 離れた位置の測定值を溶接界面での解析結果と 比較する. 解析と測定とはかなりの差があるが, 分布 形优よひ引つ張り最大沁力望月のデータを用いた方が 測定に近い結果となっている. なお，解析では厚さ方 向応力分布は中央面と溶金母材界面とで大差ないが, 測定値は差が大きい. 前述したように, 今回の測定で は母材の参照サンプルを使用しており，溶金の参照サ 
ンプルを使用していないことがこの差の原因の一つと 考えられる.

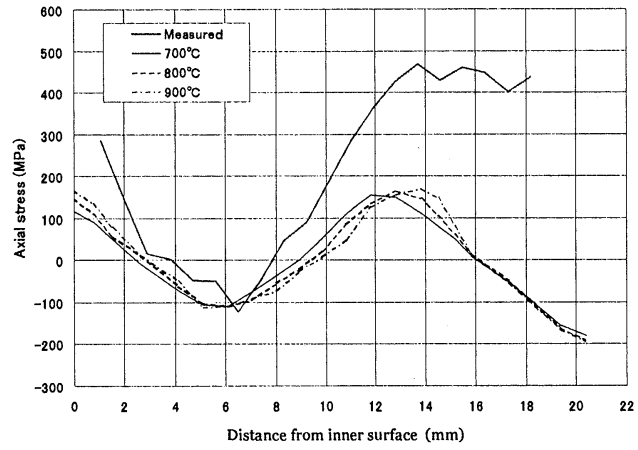

Fig. 9 The effect of anneal temperature on axial residual stress

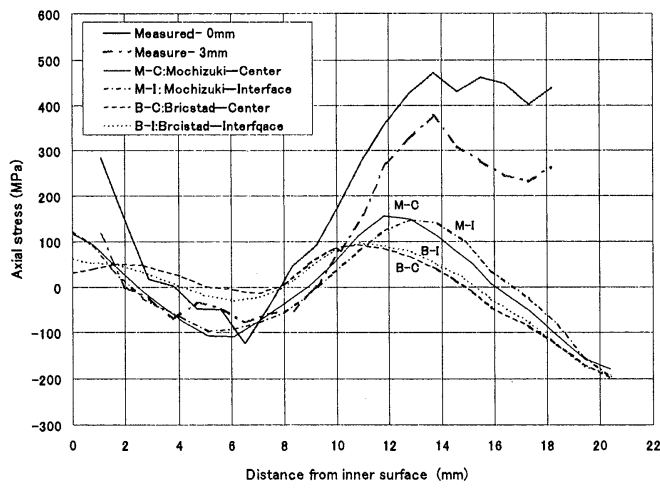

Fig. 10 The effect of stress-strain relation on axial residual stress

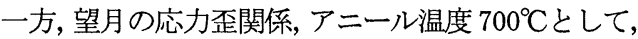
等方硬化則と移動硬化則の比較を行った結果を図 11 に示す. 分布形犾およひ引張り最大忘力に関して, 等方硬 化則を用いた方が測定に近い結果となっている.

次に，周方向の温度・応力の変化状況から，溶接 始終点の影響が小さいと考えられる周方向中央断面で の 3 次元解析結果を測定および軸対称解析結果と比較 した. 解析条件は，軸対称解析を参考にして，望月の 応力歪関係, 等方硬化則, アニール温度 $700^{\circ} \mathrm{C}$ とた. 図 12 に軸方向残留応力の厚さ方向分布を示す. 分布形 状およひ䏖張り最大忘力関して, 溶接中央および溶接界 面とも 3 次元解析結果のほうが軸対称解析よりも測定 值に近い結果を与えている.

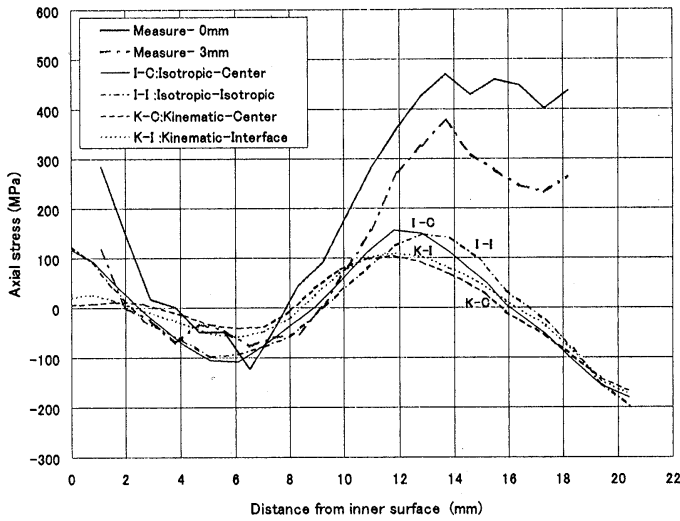

Fig. 11 Radial distribution of axial residual stress at weld center and weld interface

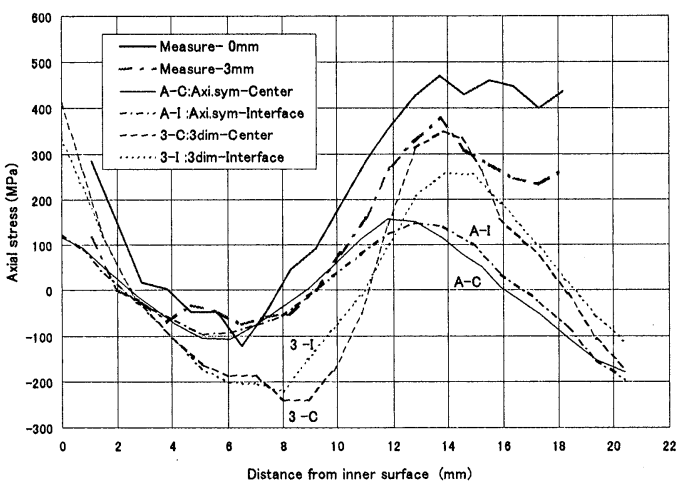

Fig. 12 Radial distribution of axial residual stress at weld center and weld interface

図 13 に軸方向残留応力の軸方向分布を示す．内面側

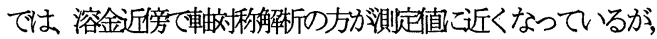
溶金力ら離れた位置では3 次元の方力測定に近くなっている。外 面側では3 次元解析の方か測定值こ近くなっている. な拉 SCC き裂発生が認められている内面側 HAZ 近傍の軸応力は 3 次元解析のほうが軸対称よりもかなり大きい.

\section{5. 応力分布がき裂進展に与える影響}

軸対称パラメトリック解析の A1 と A4 の解析結果を用 いて応力分布が SCC き裂進展に与える影響を検討した. き裂形状は内面環状き裂とし, 軸方向残留応力は厚さ 方向に線形（1次）および4 次分布で近似した. 図 14 にAPI の式 ${ }^{7)}$ で計算した応力拡大係数を示す. 


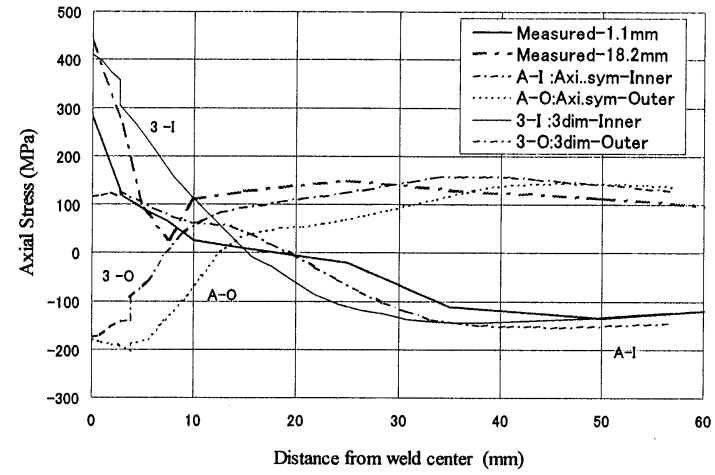

Fig. 13 Axial distribution of axial residual stress at inner and outer surface

応力桩大俉数の計算ではき裂面で広力分布を合わせる必要が あるが，4资近似応分布ではきれつ深さ $10 \mathrm{~mm}$ までの応力 分布の近似は良好であった。き裂進展特性は低炭素ス テンレス鋼に対する SCC き裂進展特性 ${ }^{8)}$ から，次式を 用いた。

$$
\begin{aligned}
& \frac{d a}{d t}=\beta \mathrm{K}^{m} \quad(\mathrm{~mm} / \mathrm{year}) \\
& \text { ここで, } \quad \beta=1.91 \times 10^{-14}, \quad \mathrm{~m}=2.161 \quad(\mathrm{MPa}-\mathrm{mm} \text { 系 })
\end{aligned}
$$

なお, 図 14 中太実線は坑力拡大俰数のき裂准展下限值であ る. 図15 にき裂隹展解析結果を示すが，本図から以下の ことが言える.

・望月のデータによる残留応力解析結果を用いた場合, 残 留応力解析結果を表す 4 次近似を用いると, 曲什応力成 分を表すと考えられる1次近似を用いた場合に比べて, き裂准展量は少ない，

・線形性の㑷 残留力分布となる Bricstad のデータを用い た場合，4次近似と 1 次近似の差は望月のデータを用い た場合に比べて, 小さい．

\section{6. 結 言}

原子力配管系の SCC 寿命評価研究の一環として, SCC の支配する主要な応力である溶接残留応力を軸対称解 析および 3 次元解析で求め, 実験結果と比較した。 ま ず，SCC 評価上重要な軸方向残留応力に及ぼす各種パ ラメータの影響を評価するため，軸対称モデルを用い た系統的な解析を行い，以下の点を明らかにした.

・ 溶接残留応力の評価において大変形の影響は小さ い.

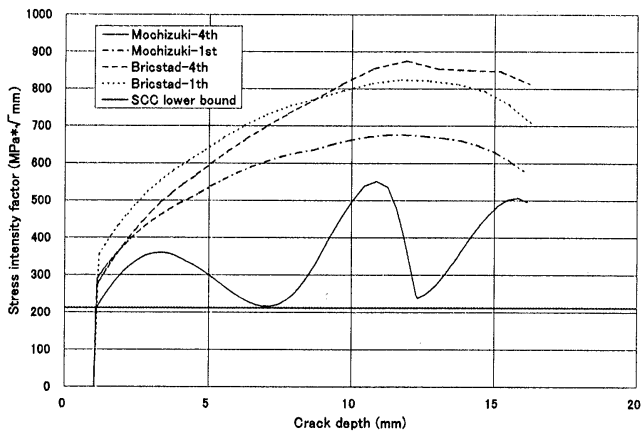

Fig. 14 The comparison of stress intensity factors for circular inner crack at weld center and weld interface

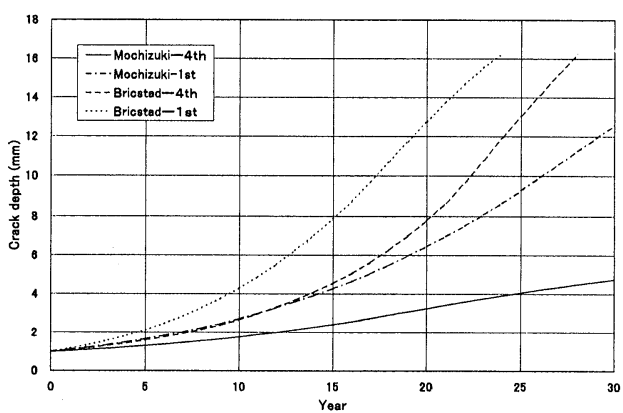

Fig. 15 SCC growth of inner circular crack

・ $700^{\circ} \mathrm{C}$ 以上の温度での塑性歪み履歴が残留応力に 与える影響は無視できる.

- 軸方向残留応力分布は材料の降伏応力および歪硬 化に依存し，これらが小さくなると自己平衡応力 成分は減少し, 相対的に周りの曲げ変形拘束に起 因する線形成分の割合が大きくなる.

次に, 軸対称および 3 次元モデルにより試験結果と の比較計算を実施し，以下の点を明らかにした。

- 内周溶接部近傍温度を測定結果と合うように溶接 入熱量を調整すれば，軸対称解析により残留応力 を推定することが可能である.

・ 実機入熱量をそのまま用いた 3 次元解析による残 留応力は測定結果とよく整合している.

- 軸方向残留応力は, 全体としては 3 次元解析の方 が軸対称解析よりも試験結果に近いが，両者の差 は小さく，温度測定結果が有れば軸対称解析によ り残留応力を評価することができる. 
さらに, 残留応力分布が SCC き裂進展に及ぼす影響に

ついて検討し, 以下の結果を得た.

・ 周りの曲げ変形拘束に起因する線形成分が大きい と，き裂進展が大きくなる

・一方, 自己平衡成分が大きいと, き裂進展は小さ くなる.

今回の検討で溶接残留応力およびその SCC に対する 影響はある程度明らかになったと思われるが，実機配 管の SCC 評価精度をより高めるためには，さらに以下 の点についての検討が必要である.

・溶接の非対称入熱を考慮した 3 次元解析.

・溶接始終点での残留応力の評価.

・残留応力の線形成分は配管剛性に大きく依存すると 思われ,配管寸法の影響を明らかにする必要がある.

\section{文献}

(1) Mochizuki, M., Enomoto, K., Okamoto, N., Saito, H. and Hayashi, E., Study on Production Mechanism of Welding Residual Stress at the Juncture of a Pipe Penetrating a Thick Plate, Transactions of the Japan Welding Society, Vol. 12, No. 4 (1994), pp. 561-567.

(2) P. Dong and F. W. Brust, Characteristic Residual Stress Distribution in Pressure Vessels and Piping Components, ASME PVP-Vol.410-1, Assensment Methodologies for Preventing Failure: Deterministic and Probabilistic Aspects and Weld Residual Stress, ASME, 2000.

(3) S. Kasa, M. Mohri, M. Tsunori, K. Sakuma, S. Hongo, Numerical Simulation for Residual Stress in Multi-pass Butt-welded Stainless Steel Pipe, Proceeding of the $8^{\text {th }}$ Weld Structure, Japan Welding Society, 2004.

(4) K. Ogawa, N. Yanagida, K. Saitou, H. Murakawa, Validation of Evaluation Methods for Residual Stress in Vessel Penetration Welds, Proceedings of the 2005 Annual Meeting of the JSME/MMD, 2005.

(5) S. K. Math and C. Watson, New UK research program on residual stresses, ASME PVP2006, PVP2006-ICPVT-11-93567, 2006

(6) B. Brickstad and B. L. Josefson, A parametric study of residual stresses in mult-pass butt-welded stainless steel pipes, Pressure Vessels and Piping, Vol.75, No. 3(1998), pp. $11-25$.

(7) ASME/API Joint Fittness for Service Standards (2001 Draft).

(8) BWR evaluation guideline for internal structure inspection, Thermal and Nuclear Power Engineering Society, 2004. 